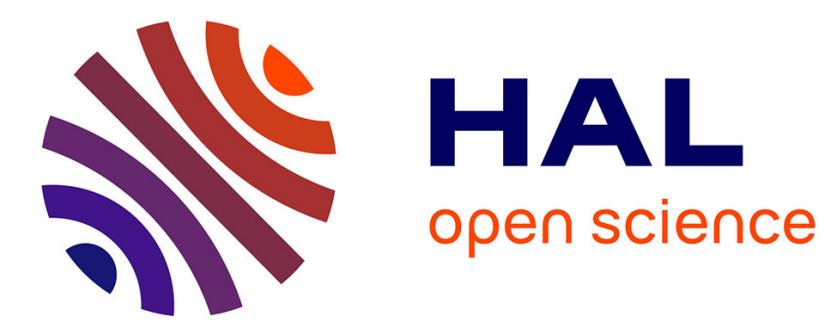

\title{
Numerical study of heat transfer in a wall of vertically perforated bricks: influence of assembly method
}

\author{
Bruno Lacarrière, Bérengère Lartigue, Françoise Monchoux
}

\section{To cite this version:}

Bruno Lacarrière, Bérengère Lartigue, Françoise Monchoux. Numerical study of heat transfer in a wall of vertically perforated bricks: influence of assembly method. Energy and Buildings, 2003, 35 (3), pp.229-237. 10.1016/S0378-7788(02)00049-X . hal-00947580

\author{
HAL Id: hal-00947580 \\ https://hal.science/hal-00947580
}

Submitted on 2 Jul 2021

HAL is a multi-disciplinary open access archive for the deposit and dissemination of scientific research documents, whether they are published or not. The documents may come from teaching and research institutions in France or abroad, or from public or private research centers.
L'archive ouverte pluridisciplinaire HAL, est destinée au dépôt et à la diffusion de documents scientifiques de niveau recherche, publiés ou non, émanant des établissements d'enseignement et de recherche français ou étrangers, des laboratoires publics ou privés. 


\title{
Numerical study of heat transfer in a wall of vertically perforated bricks: influence of assembly method
}

\author{
B. Lacarrière ${ }^{\mathrm{a}, \mathrm{b}, *}$, B. Lartigue ${ }^{\mathrm{b}}$, F. Monchoux ${ }^{\mathrm{b}}$

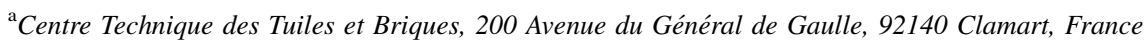 \\ ${ }^{\mathrm{b}}$ Laboratoire Etude des Systèmes et de l'Environnement Thermique de l'Homme, Université Paul Sabatier, \\ 118 Route de Narbonne, 31062 Toulouse, France
}

\begin{abstract}
Vertically perforated bricks were developed with the view to building environmentally friendly houses since they make insulating materials unnecessary. Indeed, walls can be constructed without any other materials than clay and mortar. Furthermore, they offer better mechanical properties than horizontally perforated ones. However, heat transfer in this geometry, and particularly the influence of the assembly method, is not totally known. In this numerical study, we propose to verify that convection heat transfer is negligible in the perforations. This condition is necessary to increase the thermal resistance of the brick. We then show that a masonry bedded on several strips does not penalize the thermal performance of the wall. A particular study of the ruptures concludes that the convection present in these regions is a local phenomenon preferable to the thermal bridges caused by continuous mortar joints.
\end{abstract}

Keywords: Vertically perforated brick; Convection; Numerical study

\section{Introduction}

Vertically perforated bricks are known to have better mechanical properties than the horizontally perforated ones. They were principally developed in order to build walls without necessitating any other insulating materials than the air located in the perforations. The purpose is to limit heat transfer through the wall as much as possible.

The first step in this direction is to be sure that convection transfer in the perforations is negligible compared to conduction. It is necessary to verify what kind of heat transfer occurs in the cavities once the wall has been built and whether the dimensions chosen for the cavities permit heat transfer by convection (which would decrease the wall's thermal resistance) to be neglected. In fact, in the existing products, the cell dimensions are fixed principally in the aim of obtaining homogeneous baking, necessary for homogeneous mechanical properties.

The second step concerns how the bricks are assembled. In building engineering, joints are known to be thermal bridges, reducing the insulating properties of the wall and favoring the appearance of moisture. So, when vertically

\footnotetext{
* Corresponding author.

E-mail address: lacarriere@sphinx.ups-tlse.fr (B. Lacarrière).
}

perforated bricks are used, joints are made by a succession of mortar and air strips in order to reduce the thermal bridge influence (Fig. 1). However, these ruptures in the joints allow communication among several cells (number varies with the width of the air strips) from a row of bricks to another, creating tall cavities throughout the height of the wall. Masonry bedded on several strips could be a good solution against thermal bridges if only conduction is considered. Indeed, the thermal conductivity of air $\left(\lambda_{\mathrm{a}}=0.025 \mathrm{~W} / \mathrm{m} \mathrm{K}\right)$ is very low compared to those of mortar $\left(\lambda_{\mathrm{M}}=0.7 \mathrm{~W} / \mathrm{m} \mathrm{K}\right)$ or clay $\left(\lambda_{\mathrm{cl}}=0.5 \mathrm{~W} / \mathrm{m} \mathrm{K}\right)$. But it is necessary to study the influence of communication among cavities as well as heat transfer in the ruptures and their consequences on the thermal resistance of the wall.

In a differentially heated closed cavity, flow is due to the variation of fluid density with temperature. The air rises in contact with the hot face and falls along the cold one. Batchelor [1] first studied this problem. He showed the existence of two transfer regimes: the boundary layer one and the conduction one. His results were confirmed later by Eckert and Carlson [2] and then by Elder [3]. The system we are interested in is used to thermally insulate constructions; that is why it is necessary to ensure that the heat transfer in cavities is small. Many studies exist concerning heat transfer in cavities. The ones presenting a frontier between 


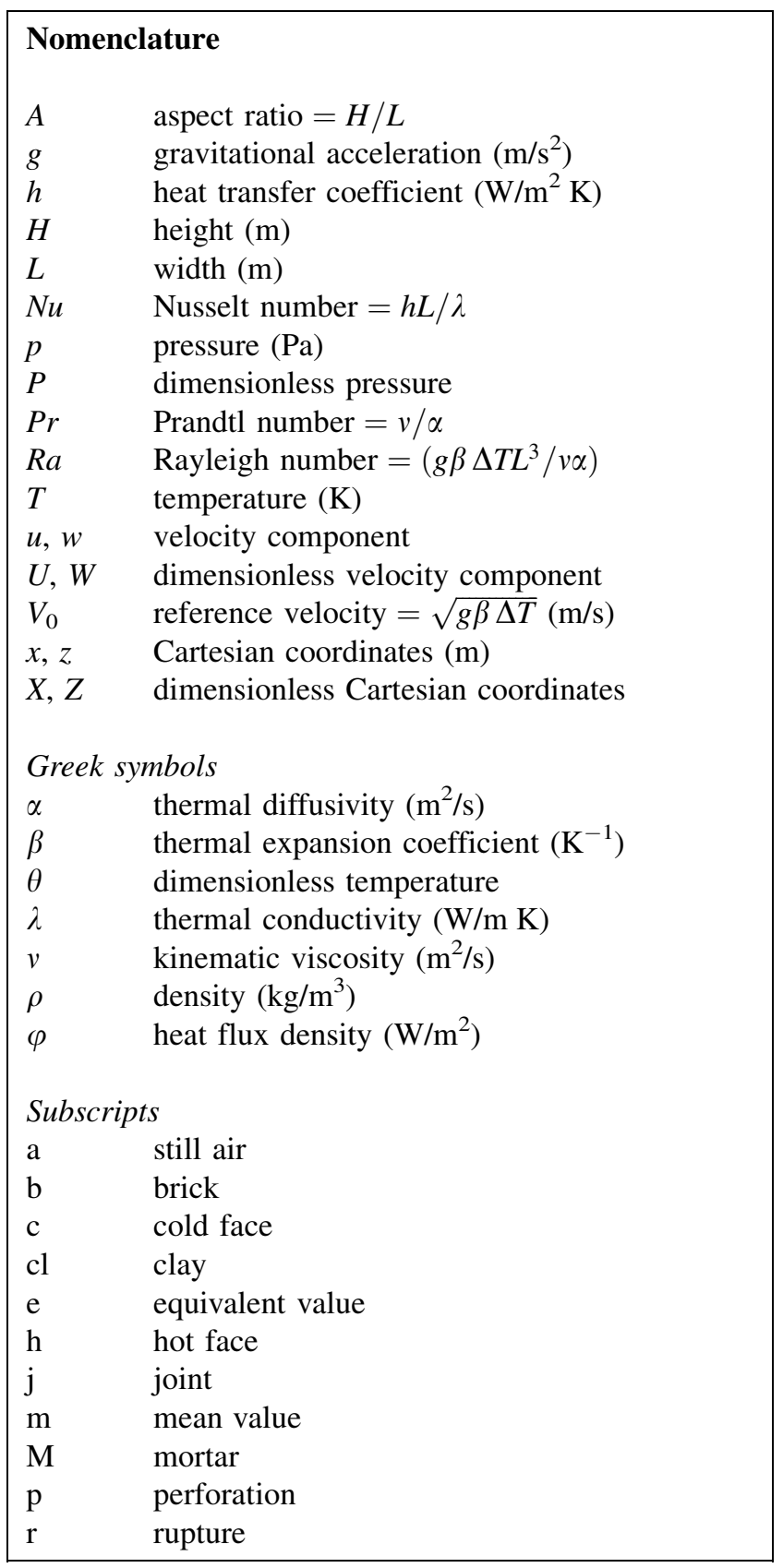

conduction regime and convection regime are of interest here. The frank limit first proposed by Batchelor [1] has been superseded by a transition zone [2,4]. Vertical air cavities of large aspect ratio have also been studied [5-8].

More recently, studies concern cavities vertically divided by partitions. These geometries are realistic representations of systems of vertically perforated bricks. Anderson and Bejan [9] took an interest in the influence of the number of partitions on the heat transfer. They experimentally and theoretically found that segmenting a cavity with two vertical partitions reduced the heat transfer $20 \%$ more than dividing the same cavity with a single partition.

Kangni et al.'s [10] works are about convection and conduction in a cavity divided by multiple partitions with finite thickness and thermal conductivity. For different values of Rayleigh number, they studied the influence of brick dimensions, partition thickness and fluid-solid conductivity ratio. This numerical study concluded that the heat transfer diminishes when the number or thickness of partitions increases. Moreover, the partitions located in the central area of the brick seem to be more efficient than the others for thermal insulation. Finally, Nusselt number decreases as the brick aspect ratio rises.

A similar work by Turkoglu and Yücel [11] confirms that the average Nusselt number decreases as the number of partitions increases, approaching an asymptotic value. What is more, it diminishes little as the aspect ratio rises, but average $N u$ increases with $R a$. This succession of air cavities and conduction partitions could be a good representation, in two dimensions, of vertically perforated bricks. But the above studies only consider cavities closed at each extremity, which is not always the reality in walls built with this kind of bricks.

This article proposes a numerical study of the flow and the heat transfer in a geometry supposed to represent stacked vertically perforated bricks. They are assembled by joints constituted by varying width mortar and air strips. The thermophysical properties are close to reality. In a first part, it will be verified that convection heat transfer can be neglected in closed cavities. In a second part, the influence of a masonry bedded on several strips on the global heat transfer will be established. Particular attention will be paid to what exactly happens in the air area located in the joint and what the consequence of perforations communication are on the wall's thermal resistance.

\section{Governing equations and numerical code}

In the aim of characterizing heat transfer in the wall, the stacking of three bricks was studied, as shown in Fig. 1, which represents the geometry and boundary conditions. Radiative transfer was not considered in this study, so heat was transferred through the brick by conduction in clay and supposed convection in air. Two-dimensional steady heat transfer in a brick of height $H_{\mathrm{b}}$ and width $L_{\mathrm{b}}$ was considered. Constant uniform temperatures $T_{\mathrm{h}, \mathrm{b}}$ and $T_{\mathrm{c}, \mathrm{b}}$ were imposed at the left and right vertical sides, respectively. The top and bottom walls were assumed thermally insulated. The coordinate system was defined so that the vertical axis $(O z)$ pointed upward in the direction opposite to gravity. The $x$ axis was horizontal. The brick was composed of perforations of height $H_{\mathrm{b}}$ and width $L$. Inside a cavity, vertical limit temperatures were $T_{\mathrm{h}}(z)$ and $T_{\mathrm{c}}(z)$. The horizontal limits depended on the perforations considered.

Laminar natural convection is governed by the continuity, Navier-Stokes and energy equations. The temperature difference was assumed small enough for the Boussinesq approximation to hold [12]. The assumptions of an incompressible flow and constant air properties (calculated at 


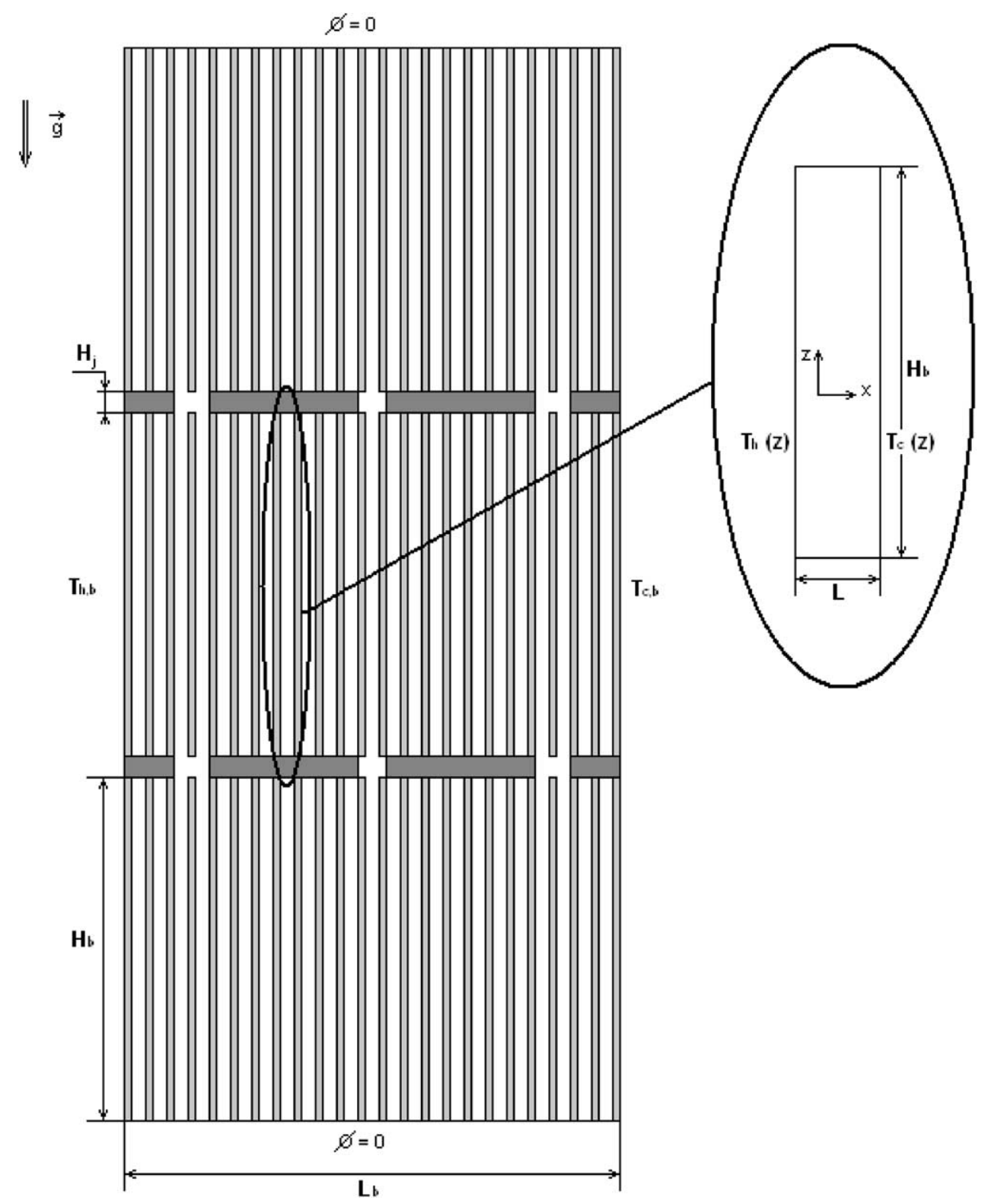

Fig. 1. Geometry studied: masonry bedded on several strips constituted by three bricks (vertical section).

$\left.T_{\mathrm{m}}=\left(T_{\mathrm{h}}+T_{\mathrm{c}}\right) / 2\right)$ were applied to the governing equations. These equations can be expressed in dimensionless forms using the following dimensionless variables:

$$
\begin{aligned}
& X=\frac{x}{L}, \quad Z=\frac{z}{L}, \quad A=\frac{H_{\mathrm{b}}}{L} \\
& U=\frac{u}{V_{0}}, \quad W=\frac{w}{V_{0}}
\end{aligned}
$$

with

$V_{0}=\sqrt{g \beta\left(T_{\mathrm{h}}-T_{\mathrm{c}}\right)}$

$P=\frac{p}{\rho V_{0}^{2}}$ with

$$
T_{\mathrm{m}}=\frac{T_{\mathrm{h}}+T_{\mathrm{c}}}{2}
$$

The governing equations can therefore be written in the following dimensionless forms.Continuity equation:

$\frac{\partial U}{\partial X}+\frac{\partial W}{\partial Y}=0$

Navier-Stokes equations:

$U \frac{\partial U}{\partial X}+W \frac{\partial U}{\partial Z}=-\frac{\partial P}{\partial X}+\left(\frac{P r}{R a}\right)^{1 / 2}\left(\frac{\partial^{2} U}{\partial X^{2}}+\frac{\partial^{2} U}{\partial Z^{2}}\right)$ 
$U \frac{\partial W}{\partial X}+W \frac{\partial W}{\partial Z}=-\frac{\partial P}{\partial Z}+\left(\frac{P r}{R a}\right)^{1 / 2}\left(\frac{\partial^{2} W}{\partial X^{2}}+\frac{\partial^{2} W}{\partial Z^{2}}\right)+\theta$

Energy equation:

$U \frac{\partial \theta}{\partial X}+W \frac{\partial \theta}{\partial Z}=(R a P r)^{-1 / 2}\left(\frac{\partial^{2} \theta}{\partial X^{2}}+\frac{\partial^{2} \theta}{\partial Z^{2}}\right)$

The Rayleigh number $R a$ is defined by:

$R a=\frac{g \beta\left(T_{\mathrm{h}}-T_{\mathrm{c}}\right) L^{3}}{\nu \alpha}$

and $P r$ is the Prandtl number equal to $P r=v / \alpha$ for air at $T_{\mathrm{m}}$.

Associated boundary conditions are given next.

The thermal boundary conditions on the vertical surfaces are:

$\theta=0.5, \quad$ at $X=0$

$\theta=-0.5, \quad$ at $X=\frac{L_{\mathrm{b}}}{L}$

Zero heat flux boundary conditions are considered at the top and bottom surfaces of the wall:

$\frac{\partial \theta}{\partial Z}=0, \quad$ at $Z=0$

and

$Z=\frac{3 H_{\mathrm{b}}+2 H_{\mathrm{j}}}{L}$
An orthogonal, non-uniform, staggered grid was used to represent the brick. The grid (having almost 425,000 nodes) was dense near each vertical and horizontal wall. The industrial code Fluent, based on the finite volumes method, was used to solve the set of equations.

\section{Results and discussion}

The brick studied here is similar to commercial ones, its dimensions were fixed so that perforations number and size were close to those found in real bricks. The cavity aspect ratio was consequently $A=H_{\mathrm{b}} / L=23.3$ and the previous dimensionless boundary conditions (6) and (8) were written at $X=L_{\mathrm{b}} / L=33.66$ and $Z=\left(3 H_{\mathrm{b}}+2 H_{\mathrm{j}}\right) / L=72.22$, respectively. The fluid considered was air, so $\operatorname{Pr}=$ $v / \alpha=0.71$.

Particular zones of the stack were studied in this work. The first study verified that convection could be neglected in a closed perforation. The second section presents the influence of two kinds of communication among cavities, as shown in Fig. 2.

\subsection{Single cavity}

Heat transfer in a single perforation was studied. The temperature difference was small. Fig. 3 represents the variation of dimensionless temperature $\theta$ versus the dimensionless width for different heights $Z$ in the cavity. Considering Fig. 3, $0 \leq X \leq 1$ corresponds to the air gap,

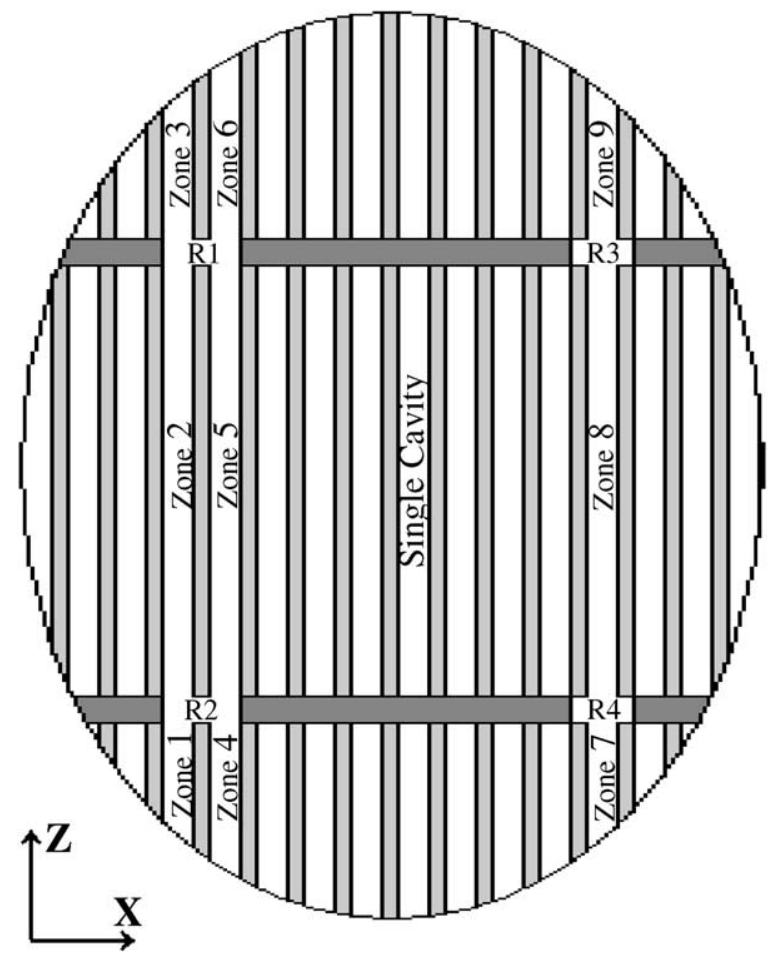

\begin{tabular}{|l|l|l|}
\hline $3,33<X<4,33$ & $4,77<X<5,77$ & $15,8<X<16,8$ \\
\hline
\end{tabular}

\begin{tabular}{|c|c|c|c|}
\hline $0<Z<23,3$ & Zone 1 & Zone 4 & Zone 7 \\
\hline $24,4<Z<47,7$ & Zone 2 & Zone 5 & Zone 8 \\
\hline $48,8<Z<72,2$ & Zone 3 & Zone 6 & Zone 9 \\
\hline
\end{tabular}

Fig. 2. Definition of the different zones. 


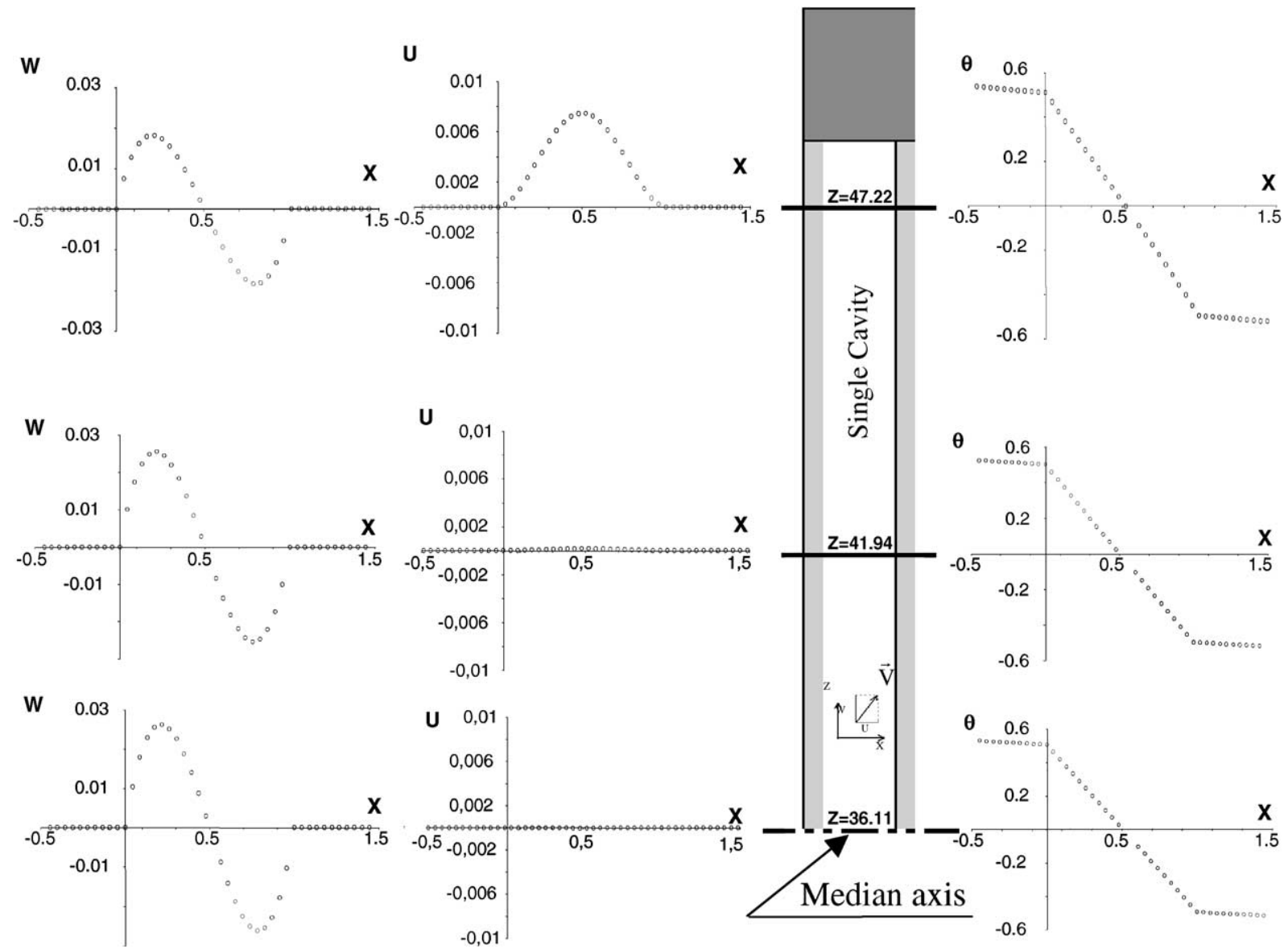

Fig. 3. Dimensionless velocity and temperature profiles vs. $X$ for various heights in a single perforation closed at both extremities-half figure.

$-0.5 \leq X \leq 0$ is in the left clay zone, $1 \leq X \leq 1.5$ is in the right one. For dimensionless heights varying from 24.44 to 47.77, the profiles present three distinct parts. In the air $(0 \leq X \leq 1)$, the variation of $\theta$ versus $X$ is linear for all heights, which is characteristic of heat transfer by conduction. In clay, the profiles are linear as expected in a solid. A usual means of characterizing heat transfer is to calculate the Nusselt number. Local Nusselt number represents the ratio of convection heat transfer over conduction heat transfer. It is calculated according to Eq. (9):

$N u(z)=\frac{h(z) L}{\lambda(T)}$

with

$$
\begin{aligned}
h(z) & =\frac{\varphi(z)}{T_{\mathrm{h}}(z)-T_{\mathrm{c}}(z)} \\
& =\left(\frac{1}{T_{\mathrm{h}}(z)-T_{\mathrm{c}}(z)}\right)\left(\lambda(T) \frac{T_{\mathrm{h}}(z)-T(x, z)}{x}\right)
\end{aligned}
$$

where $\varphi(z)$ is the parietal local flux, calculated very near the hot face, in the viscous layer. The value of $\lambda$ is evaluated locally along the vertical wall according to the temperature. Fig. 4 represents the variation of local Nusselt number versus

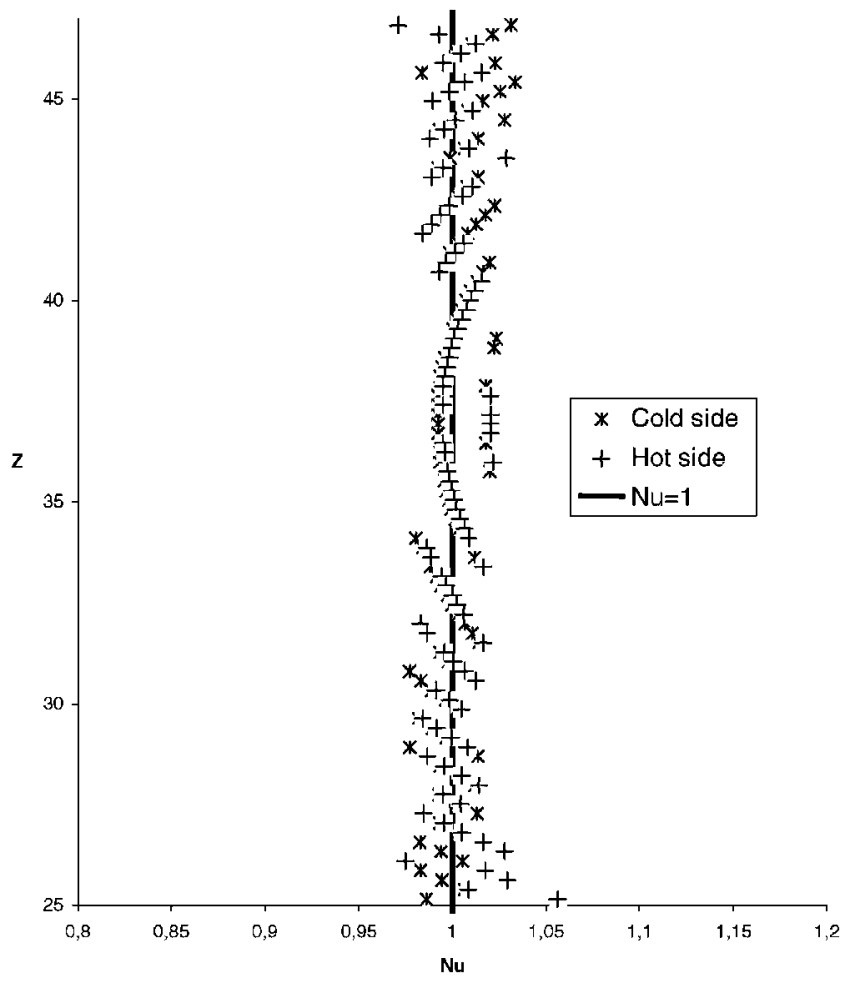

Fig. 4. $N u$ vs. $Z$ in an perforation closed at each extremity. 
height $Z$. In the cavity, $N u(Z)$ is equal to 1 , confirming that conduction dominates the heat transfer. From the knowledge of the local Nusselt number, the average Nusselt number $\mathrm{Nu}$ can be calculated by integration of the local values over the height of the cavity (11):

$N u=\frac{1}{H_{\mathrm{b}}} \int_{0}^{H_{\mathrm{b}}} N u(z) \mathrm{d} z$

The value obtained is $N u=1.013$. This value (very close to 1) characterizes heat transfer by conduction.

The dynamic field represented in Fig. 3 confirms this conclusion. The vertical component shows that fluid rises along the hot face and falls along the cold face, as expected. Except at the top and bottom of the cavity where the fluid makes a U-turn, the horizontal component is zero for the whole height of the cavity meaning there is no flow to create a boundary layer.

These results are in good agreement with those of Batchelor, Eckert and Carlson or Yin et al., presented in Fig. 5, for which limits between conduction and convection regimes are represented for various aspect ratios and various Rayleigh numbers. The present study, represented by a point, is in the conduction zone for all the authors.

\subsection{Open cavities}

If convection transfer can be neglected in the perforations totally closed by mortar, it is necessary to determine if this is always true when they are not, i.e. when there are some ruptures in the joints, to disturb the thermal bridge, as mentioned before. Two types of ruptures, close to those met in reality, are considered in this study. The first one is close to the width of an perforation while the second one allows communication between two cavities per brick (Fig. 2).

\subsubsection{Simple communication}

Up to now, the study concerns non-closed perforations. The height of the wall is divided into different zones corresponding to each brick and the thickness of each joints. The zones defined in Fig. 2 named zones 7-9, correspond to the present case. To determine the main heat transfer mode, the same method as above (Section 3.1) was used, i.e. calculation of the average Nusselt number. Table 1 shows the values obtained. They are very close to unity, which means the heat transfer is purely conductive.

The dynamic field (Fig. 6) is similar to the previous one (single cavity) for each of the zones 7-9. Velocity is low (in both directions) and temperature profiles are linear, meaning heat is still transferred by conduction.

\subsubsection{Double communication}

This case corresponds to communication among zones 1-6 (Fig. 2). The particularity of this case is the dynamic field in zones 2 and 5. Previously, the fluid rose along the hot face of a cavity and came down along the cold face of the same cavity. Here, air rises in the entire perforation located at the hot side (named zone 2 in Fig. 2) and comes down in

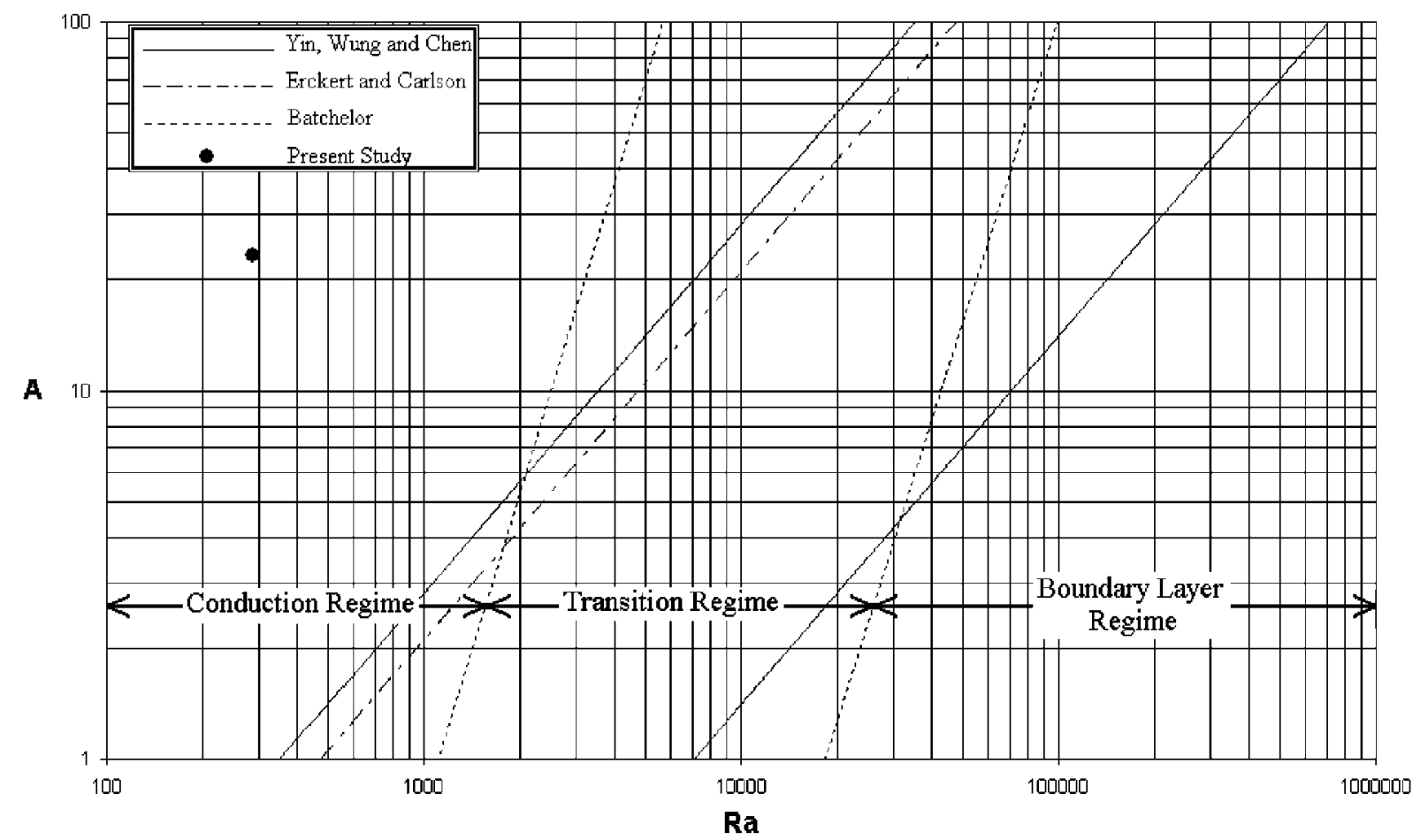

Fig. 5. Limits between conduction and convection transfer. 
Table 1

Average Nusselt numbers (simple communication)

\begin{tabular}{llll}
\hline & Zone 7 & Zone 8 & Zone 9 \\
\hline Average Nusselt number & 1.005 & 0.942 & 1.004 \\
\hline
\end{tabular}

the entire cavity, again, placed at the cold side (zone 5 in Fig. 2). This particularity is clearly shown in Fig. 7.

Moreover, the vertical velocity profiles, drawn for different heights in the middle brick are not symmetrical. Indeed, temperature is different for each face of a cavity, so air rises faster along the hot side of zone 2 and falls faster along the cold side of zone 5. This velocity is, however, small and almost zero for the horizontal component (except near the ruptures as will be explained later).

The temperature profiles in Fig. 7 are, as for the cavities previously studied, linear at each height of the two zones (except again near the joints). The rising velocity is not large, there is no thermal boundary layer along the faces (characteristic of a convection transfer) and the temperature profiles are linear. So it can be concluded that this particular flow in the middle brick does not increase the heat transfer.
Table 2

Average Nusselt numbers (double communication)

Zone 1 Zone 2 Zone 3 Zone 4 Zone 5 Zone 6

$\begin{array}{lllllll}\text { Average Nusselt number } & 1.004 & 1.001 & 1.002 & 1.01 & 1.005 & 1.01\end{array}$

The average Nusselt number in Table 2 confirms this result. These values, also close to 1 , express that conduction is the main heat transfer mode.

\subsection{The ruptures}

In Fig. 7, the temperature profiles are not linear near the ruptures and the horizontal component of velocity increases in these regions. This means that convection may not be neglected in the ruptures. This idea is confirmed by Fig. 8, which represents the temperature profile along the thickness of the wall at mid-height in a joint. This profile is not linear in the zones which correspond to the ruptures, while it is in the mortar. Table 3 presents average Nusselt number values for the four ruptures; they are clearly greater than 1 . So convection cannot be neglected in the ruptures.

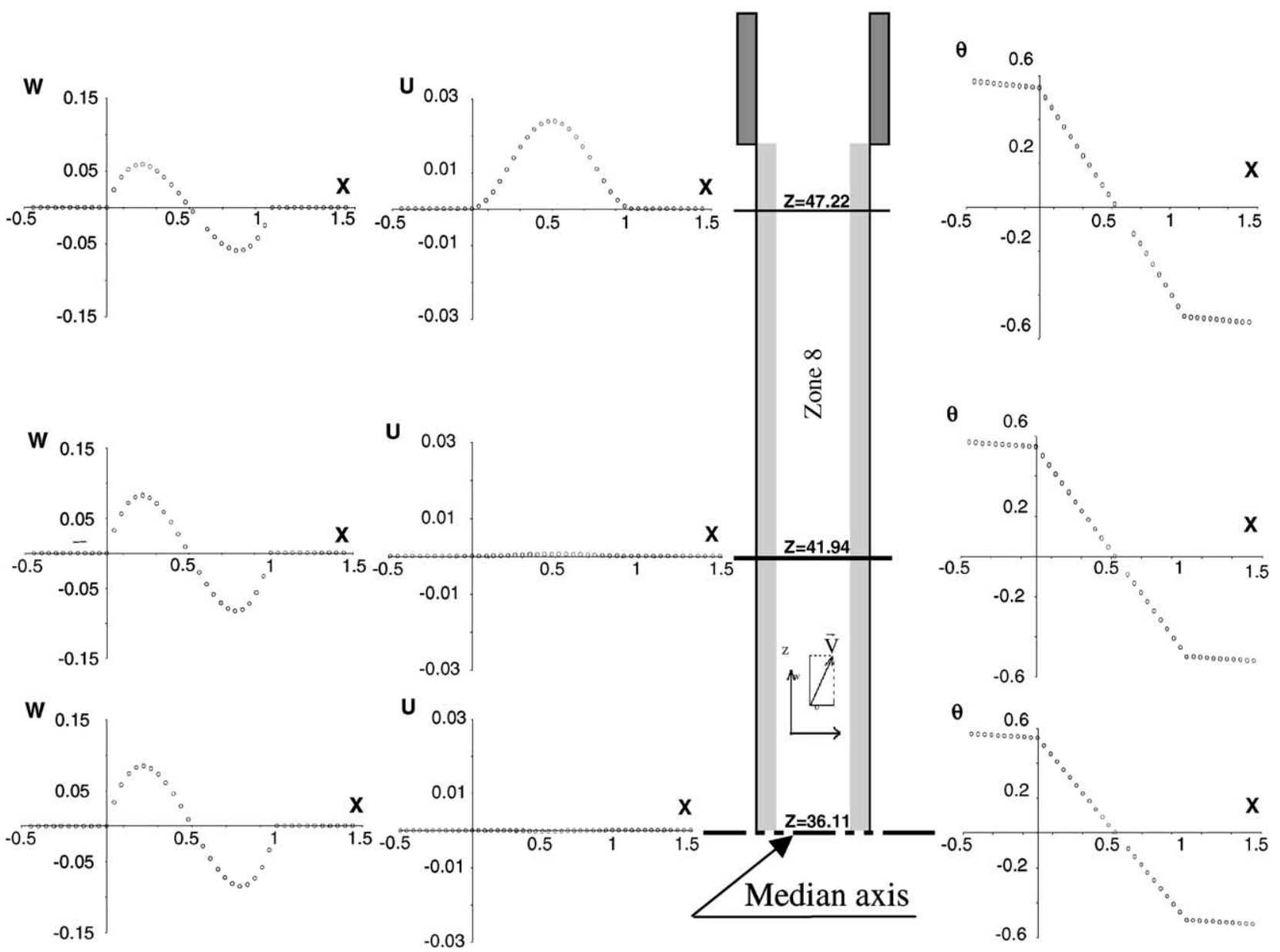

Fig. 6. Dimensionless velocity and temperature profiles vs. $X$ for various heights (simple communication)—half figure. 


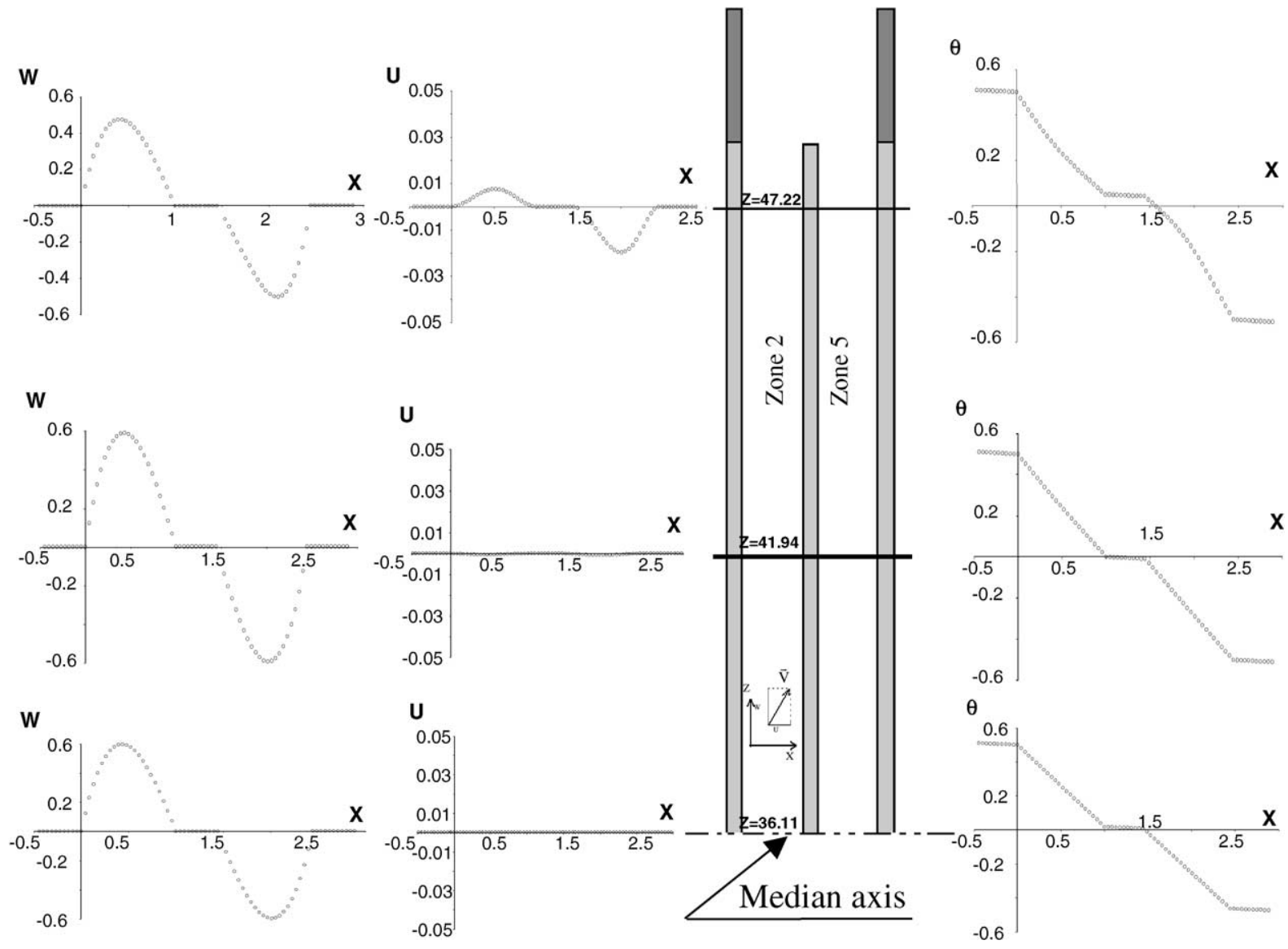

Fig. 7. Dimensionless velocity and temperature profiles vs. $X$ for various heights (double communication)—half figure.

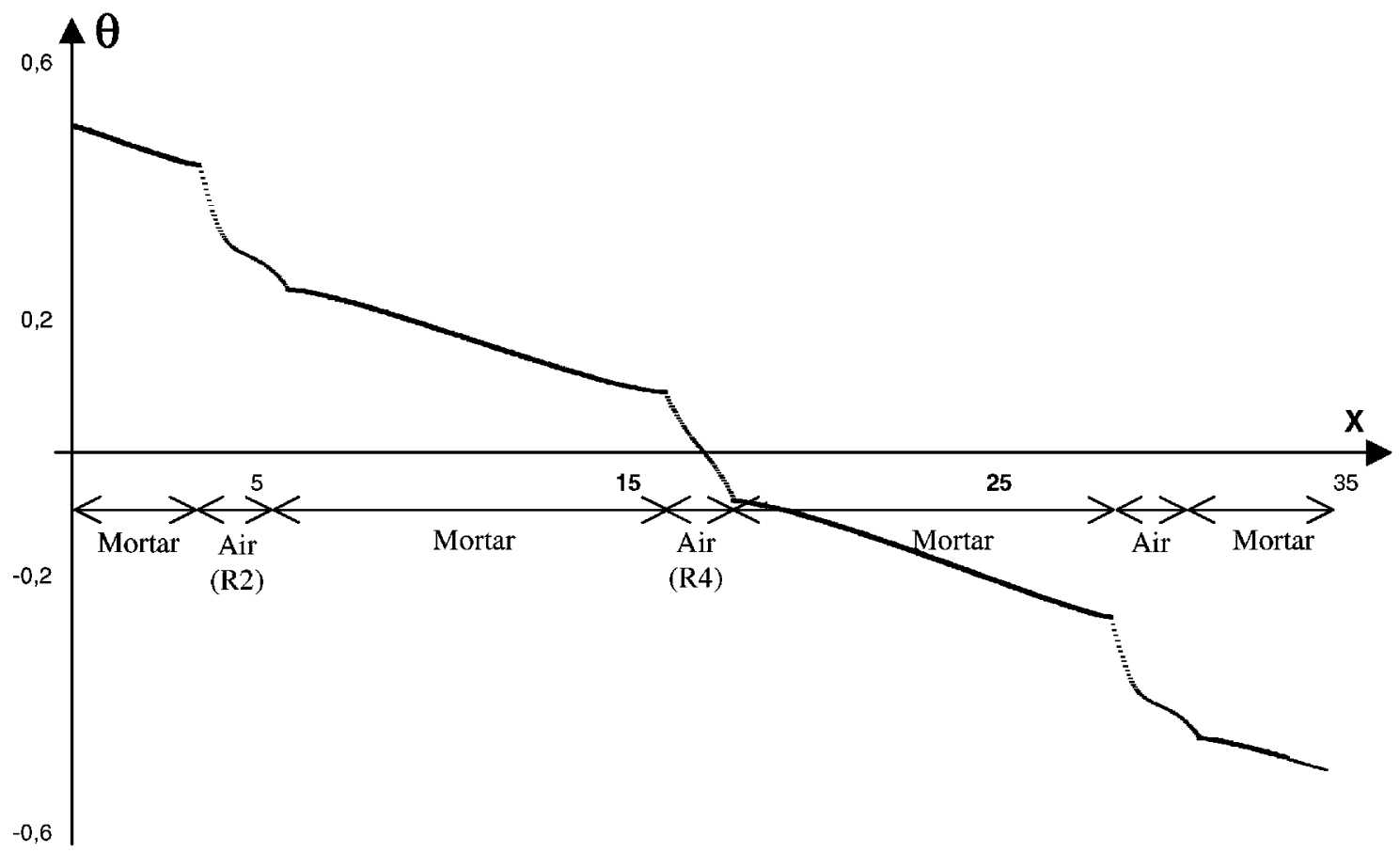

Fig. 8. Dimensionless temperature profile along the wall thickness at mid-height of a joint. 
Real case

(Convection + Conduction)
Model case

(Conduction)
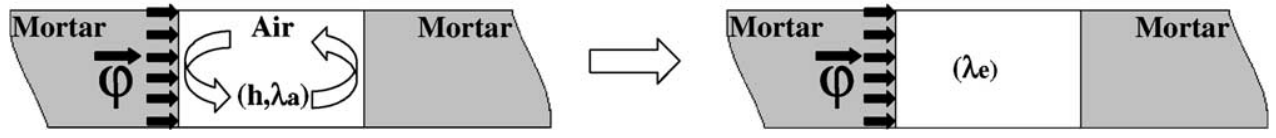

Fig. 9. Determination of rupture equivalent conductivity when assimilated to a solid.

Table 3

Average Nusselt numbers in ruptures

\begin{tabular}{lllll}
\hline & R1 & R2 & R3 & R4 \\
\hline Average Nusselt number & 1.728 & 1.752 & 1.891 & 1.89 \\
\hline
\end{tabular}

By calculating the heat flux density crossing the ruptures, it is possible to determine an equivalent conductivity (12), for air in the ruptures, which represents both the transfers: conduction and convection (Fig. 9):

$\lambda_{\mathrm{e}}=\frac{\varphi_{\mathrm{m}} L_{\mathrm{r}}}{T_{\mathrm{h}, \mathrm{r}}-T_{\mathrm{c}, \mathrm{r}}}$

The mean flux density $\varphi_{\mathrm{m}}$ is obtained by integration of the local heat flux density (calculated as for the Nusselt number evaluation in Section 3.1) along the rupture height.

It was found $\lambda_{\mathrm{e}}=0.046 \mathrm{~W} / \mathrm{m} \mathrm{K}$ for the small ruptures and $\lambda_{\mathrm{e}}=0.044 \mathrm{~W} / \mathrm{m} \mathrm{K}$ for the large ones. These values are certainly greater than the conductivity for still air $\left(\lambda_{\mathrm{a}}=0.025 \mathrm{~W} / \mathrm{m} \mathrm{K}\right)$ but they are a lot smaller than mortar conductivity (fixed to $\lambda_{\mathrm{M}}=0.7 \mathrm{~W} / \mathrm{m} \mathrm{K}$ in this work, which corresponds to a lightened mortar). So the ruptures have the expected effect: they disturb the thermal bridge caused by joints.

\section{Conclusion}

The width chosen for the perforations in the vertically perforated bricks respects manufacturing constraints (broad enough to obtain homogenous baking) and the insulating properties expected for the wall (not too wide in order to prevent convection). The masonry bedded on several strips, does not diminish the insulating power of the bricks themselves, neither when only one perforation per brick is not closed nor when there is communication between two cavities per brick. Convection in the ruptures cannot be neglected and increases the heat transfer but ruptures are nevertheless necessary when traditional mortar is used.
Ruptures create zones with an equivalent thermal conductivity weaker than mortar conductivity.

\section{Acknowledgements}

This study was carried out with the collaboration of Alain Trombe (INSA Toulouse) and financial support of the Centre Technique des Tuiles et Briques (CTTB), France.

\section{References}

[1] G.K. Batchelor, Heat transfer by free convection across a closed cavity between vertical boundaries at different temperatures, Quarterly of Applied Mathematics 12 (1954) 209-233.

[2] E.R.G. Eckert, W.O. Carlson, A natural convection in air layer enclosed between two vertical plates with different temperatures, International Journal of Heat and Mass Transfer 11 (1961) 106-120.

[3] J.W. Elder, Laminar free convection in a vertical slot, Journal of Fluid Mechanics 23 (1965) 77-98.

[4] S.H. Yin, T.Y. Wung, K. Chen, Natural convection in an air layer enclosed within rectangular cavities, International Journal of Heat and Mass Transfer 21 (1978) 307-315.

[5] G.D. Raithby, H.H. Wong, Heat transfer by natural convection across vertical air layers, Numerical Heat Transfer 4 (1981) 447-457.

[6] S.M. Elsherbiny, G.D. Raithby, K.G.T. Hollands, Heat transfer by natural convection across vertical and inclined air layers, ASME Journal of Heat Transfer 104 (1982) 96-102.

[7] J.L. Wright, H.F. Sullivan, A two dimensional numerical model for natural convection in a vertical, rectangular window cavity, ASHRAE Transactions 100 (1994) 1193-1206.

[8] E. Shewen, K.G.T. Hollands, G.D. Raithby, Heat transfer by natural convection across a vertical air cavity of large aspect ratio, Journal of Heat Transfer 118 (1996) 993-995.

[9] R. Anderson, A. Bejan, Heat transfer through single and double vertical walls in natural convection: theory and experiment, International Journal of Heat and Mass Transfer 24 (1981) 1611-1620.

[10] A. Kangni, B. Yedder, E. Bilgen, Natural convection and conduction in enclosures with multiple vertical partitions, International Journal of Heat and Mass Transfer 34 (1991) 2819-2825.

[11] H. Turkoglu, N. Yücel, Natural convection heat transfer in enclosures with conducting multiple partitions and side walls, Heat and Mass Transfer 32 (1996) 1-7.

[12] D.D. Gray, A. Giorgini, The validity of the Boussinesq approximation for liquids and gazes, International Journal of Heat and Mass Transfer 19 (1976) 545-551. 